\title{
Disclosure of herbal medicine use to health care providers among pregnant women in Nepal: a cross-sectional study
}

\author{
Mansoor Ahmed ${ }^{1,2}$, Hyea Bin $\mathrm{Im}^{2,3}$, Jung Hye Hwang ${ }^{2,3,4}$ and Dongwoon Han 2,3, $^{*}$ (D)
}

\begin{abstract}
Background: Pregnant women's disclosure of herbal medicine (HM) use to their health care providers during pregnancy is crucial, as misuse of HM can have a detrimental effect on both pregnant woman and the fetus. However, the lack of disclosure of HM use to physicians remains a public health concern in developing countries such as Nepal.

Methods: A cross-sectional study was conducted among 400 postpartum women admitted at Maternity and Women's Hospital located in Kathmandu, Nepal. The survey instrument included 30 questions on the use of HM during pregnancy, sociodemographic and health characteristics, and pregnancy outcomes. Chi-square test and logistic regression were conducted for data analysis using SPSS ver. 21.0., and a $p$-value of less than 0.05 was considered statistically significant for all analyses.

Results: $60.3 \%$ of respondents used at least one herbal remedy during their previous pregnancy, and the overall disclosure rate of HM use to healthcare providers was 54.6\%. Women with secondary education level and four or more antenatal care visits were more likely to disclose their HM use to healthcare providers.

Conclusions: This study highlights that despite the popular use of HM among pregnant women in Nepal, most women obtained HM-related information from informal sources and did not disclose their HM use to physicians. To ensure the safe use of HM, physicians should integrate questions regarding patients' HM use into their routine patient assessments to facilitate active communication and improve the quality of care.
\end{abstract}

Keywords: Physician-patient communication, Patient disclosure, Herbal medicine, Pregnancy, Nepal

\section{Background}

The World Health Organization defines herbal medicines $(\mathrm{HM})$ as various forms of herbal products and preparations containing active ingredients of plants [1]. Globally, the practice of HM use is widespread among pregnant women to treat common health problems for various reasons, such as cultural influences, easy

\footnotetext{
* Correspondence: dwhan@hanyang.ac.kr

${ }^{2}$ Department of Global Health and Development, Graduate School, Hanyang University, Seoul, South Korea

${ }^{3}$ Institute of Health Services Management, Hanyang University, Seoul, South Korea

Full list of author information is available at the end of the article
}

accessibility, and cost-effectiveness of herbal products [2, 3]. The prevalence of HM use, which ranges from 1 to $63 \%$, is notably greater in countries like Taiwan and Hong Kong, where traditional medicine use is widely accepted $[3,4]$. However, misuse of HM during pregnancy remains a public health concern as pregnant women are more vulnerable to various physical and mental health issues [5-7]. The pharmacological characteristics of certain herbs can have a detrimental effect on both pregnant woman and the fetus $[5,8]$, and it was found that HM use is often self-prescribed and is unsupervised by health professionals $[6,7,9]$. 
One of the ways to prevent inappropriate use of HM is to increase patient disclosure of HM use to physicians, on the premise that the physicians have appropriate knowledge of herbs' activity. It is because improved physician-patient communication on HM use provides an opportunity for appropriate medical intervention when complications or adverse reactions arise from concurrent use of HM and conventional medicine [10, 11]. Despite the importance of transparent communication between physicians and patients, previous research has found that 33 to $95 \%$ of pregnant women did not tell their healthcare providers about HM use simply because they were not asked or concerned about negative attitudes of medical doctors on HM use $[3,4,6]$.

Previous studies have identified various socioeconomic characteristics and healthcare utilization patterns to be associated with disclosure of HM use, and specifically, increased use of medical services was found to be associated with increased patient disclosure of HM use to healthcare providers [11]. Similarly, attending regular antenatal checkups (ANC) during pregnancy not only provides the healthcare providers to treat and monitor potential health problems, but also allows pregnant women to address concerns and questions about self-care activities during pregnancy, such as HM use [12, 13]. However, the potential association between frequent physician visits and disclosure of HM use among pregnant women has not been fully explored.

In Nepal, the use of HM is also widespread and is culturally embedded [14], yet little is known about the pattern of HM use during pregnancy, whether proper physician-patient communication on HM use has been practiced, and which factors are associated with disclosure of HM use to healthcare providers [14-16]. Therefore, this study aims to explore the pattern of $\mathrm{HM}$ use among pregnant women in Nepal, to examine the prevalence of disclosure of HM use during pregnancy, and to identify the factors associated with the disclosure of HM use to physicians during pregnancy.

\section{Methods}

\section{Study setting and participants}

A descriptive cross-sectional study was conducted among postpartum women admitted at Maternity and Women's Hospital located in Kathmandu, Nepal. All postpartum women between the ages of 16 and 49 were invited to participate in the survey, and the survey was taken before they were discharged from the hospital to minimize the recall bias. Pregnant women with any type of disabilities or who were currently receiving treatment for a severe condition at a high dependency or an intensive care unit were excluded from participation.

\section{Study size}

The sample size was calculated based on the formula for sample size determination using confidence interval (CI) of proportion: $n=z_{\alpha / 2}^{2} \cdot \frac{p q}{d^{2}}$. The margin of error was set at 0.05 with $95 \%$ confidence interval. Additionally, because there was no previous study on the use of HM among pregnant women in Nepal, a study from Malaysia was adopted as a reference for the estimated proportion of HM use during pregnancy (0.524) [17]. This equation gave us the minimum sample size of 383 , and a total of 460 participants were invited to join the study to account for a $20 \%$ non-response rate.

\section{Survey instrument}

After reviewing the literature $[6,18,19]$, the semistructured survey questionnaire was developed in English and then translated into the Nepali language to suit the target population. The Nepali questionnaire was back-translated into English to confirm the linguistic validity. In order to assess the content and face validity of the survey instrument, the questionnaire was reviewed by two physicians working in the obstetrics department at the study site and a healthcare practitioner at a local traditional medicine clinic for clarity, relevance, appropriateness, adequacy, and organization of the questions. The questionnaire was also pilot-tested on a sample of 20 participants to examine the length, clarity, and difficulty of the questions, and based on the results, a few items were modified into its final version.

The final version of the questionnaire contained 30 items with a combination of multiple-choice and openended questions (See Additional file 1: Survey Questionnaire). The survey was divided into four major sections. The first part of the questionnaire included seven questions regarding the medical characteristics of participants, such as current health-status measured in 5-point Likert scale, type of delivery, obstetric history, smoking status, number of antenatal care visits, complications experienced during pregnancy, labor, and after birth. The second part of the survey contained 12 questions concerning HM use during pregnancy (i.e., history of HM use before pregnancy, use of HM during pregnancy, types of modalities used and their indications, the reason for use and non-use, frequency of HM use, level of satisfaction, the experience of adverse effects, source of information, and disclosure of HM use to physicians). The third section comprised of five questions on characteristics of the newborn baby (i.e., gestational age at birth, gender, weight, congenital malformations, and neonatal symptoms experienced such as breathing problems, newborn jaundice, tender abdomen, temperature problems, bowel problems, lethargy, cardiac symptoms, and convulsions). The final section included six items on 
sociodemographic characteristics of respondents such as age, area of residence, education level, employment status, monthly household income, and traveling time from the nearest health facility.

\section{Data collection}

The face-to-face interviews were conducted from July 4th, 2017 to August 12th, 2017. One supervisor and four data collectors were recruited for data collection. All participation was voluntary, and IRB-approved informed consent was obtained before the survey. In addition, information on complications during labor and after childbirth, as well as the characteristics of the newborn baby were obtained with the help of hospital staff. A total of 460 women were invited to participate in the study, and 400 completed the survey ( $87 \%$ response rate).

\section{Statistical methods}

Although data from 400 participants were obtained, the current study focuses on disclosure of HM use to physicians during pregnancy, rather than general information around HM use among pregnant women. Therefore, only the data from $241 \mathrm{HM}$ users were included in the final analysis. The data of $241 \mathrm{HM}$ users were analyzed using the Statistical Package for Social Sciences (SPSS) version 21.0. Descriptive statistics were computed to examine sociodemographic and HM use-related characteristics of the respondents. Quantitative variables were grouped as follows: respondent's age was grouped by 10year increments (i.e., "less than 20 years old," "between 21 and 30," and "more than 31 years old"), and newborn baby's birth weight was grouped by $5.0-\mathrm{kg}$ increments starting from $2.5 \mathrm{~kg}$ (i.e., "less than $2.5 \mathrm{~kg}$," "between 2.5 and $3.0 \mathrm{~kg}$," and "more than $3.0 \mathrm{~kg}$ "), as birth weight less than $2.5 \mathrm{~kg}$ are considered low birth weight. Pearson's Chi-square test was performed to identify differences in sociodemographic and medical characteristics between those who revealed HM use to physicians during pregnancy and those who did not. Furthermore, variables that were statistically significant in the Chi-square test were included in regression for further analysis. The multivariate logistic regression analysis was conducted to determine factors associated with disclosure of $\mathrm{HM}$ use to physicians during pregnancy. A $p$-value of less than 0.05 was considered statistically significant for all analyses.

\section{Ethical clearance}

The ethical approval of the study was given by the Institutional Review Board on Human Subjects Research and Ethics Committees, Hanyang University, Seoul, Korea (HYI-17-067-2). Additionally, formal permission to carry out the study was granted by the ethical body of the
Maternity and Women's Hospital in Kathmandu, Nepal (58-11 ka-259).

\section{Results \\ Sociodemographic and pregnancy-related characteristics of study participants}

Sociodemographic and pregnancy-related characteristics of respondents are presented in Table 1 . The majority of respondents were between 21 and 30 years old (70.5\%), received primary education or no education $(52.3 \%)$, and were not employed (81.7\%). As for pregnancy-related characteristics, most respondents experienced full-term pregnancy (91.3\%), had normal delivery (62.2\%), attended ANC four or more times (87.6\%), and did not experience any complications during pregnancy (64.3\%) or childbirth (58.1\%).

$54.8 \%$ of respondents disclosed HM use to healthcare professionals. Significant differences between the group who disclosed HM use to physicians and those who did not disclose HM use were observed in their education level $(p<0.001)$, employment status $(p=0.008)$, household income $(p=0.015)$, residential area $(p<0.001)$, type of delivery $(p=0.036)$, number of ANC visits $(p<0.001)$, the experience of complications during and after childbirth $(p=0.001)$, and experience of newborn complications $(p=0.023)$.

\section{Types of HM used during pregnancy and reported indications}

Table 2 shows the types of HM modalities used by respondents during pregnancy. Consumption of ginger (46.1\%) and turmeric (43.2\%) were the highest, followed by lemon tea (29.5\%), tulsi (24.5\%), and olive oil (12.0\%). The most commonly reported indications for HM use (not shown in Tables) were cough, cold, and flu (72.6\%), nausea and vomiting (39.8\%), and heartburn and indigestion $(23.6 \%)$.

\section{Source of information on HM}

As presented in Table 3, the primary source of information regarding HM use was family, friends, or neighbors (98.3\%) and newspapers or magazines (17.1\%). 4.6\% of respondents obtained HM information from doctors.

\section{Reasons for HM use and non-disclosure of HM use to physicians}

The most common reason for HM use among pregnant women was due to its perceived safety (66.4\%), followed by family tradition and culture $(63.1 \%)$ and perceivedeffectiveness in treating their conditions (48.1\%). Regarding the reason for non-disclosure of HM use to healthcare providers, $39.8 \%$ responded that doctors did not ask, and $29.6 \%$ reported that they did not think it was important to tell the doctors about their use (Table 4). 
Table 1 Sociodemographic characteristics of respondents

\begin{tabular}{|c|c|c|c|c|}
\hline Characteristics & $\begin{array}{l}\text { Total } \\
n=241(\%)\end{array}$ & $\begin{array}{l}\text { Disclosed HM use } \\
n=132(\%)\end{array}$ & $\begin{array}{l}\text { Did not disclose } \\
n=109(\%)\end{array}$ & $P$-value \\
\hline \multicolumn{5}{|l|}{ Age (years) } \\
\hline$<20$ & $43(17.8)$ & $19(14.4)$ & $24(22.0)$ & \multirow[t]{3}{*}{0.220} \\
\hline $21-30$ & $170(70.5)$ & $99(75.0)$ & $71(65.1)$ & \\
\hline$\geq 31$ & $28(11.6)$ & $14(10.6)$ & $14(12.8)$ & \\
\hline \multicolumn{5}{|l|}{ Education level } \\
\hline Primary and under & $126(52.3)$ & $54(40.9)$ & $72(66.1)$ & \multirow[t]{3}{*}{$<0.001$} \\
\hline Secondary & $77(32.0)$ & $54(40.9)$ & $23(21.1)$ & \\
\hline College or above & $38(15.8)$ & $24(18.2)$ & $14(12.8)$ & \\
\hline \multicolumn{5}{|l|}{ Employment status } \\
\hline Yes & $44(18.3)$ & $32(24.2)$ & $12(11.0)$ & \multirow[t]{2}{*}{0.008} \\
\hline No & $197(81.7)$ & $100(75.8)$ & $97(89.0)$ & \\
\hline \multicolumn{5}{|l|}{ Household income } \\
\hline Low & $72(29.9)$ & $30(22.7)$ & $42(38.5)$ & \multirow[t]{3}{*}{0.015} \\
\hline Middle & $52(21.6)$ & $28(21.2)$ & $24(22.0)$ & \\
\hline High & $117(48.5)$ & $74(56.1)$ & $43(39.4)$ & \\
\hline \multicolumn{5}{|l|}{ Residence } \\
\hline Rural & $115(47.7)$ & $49(37.1)$ & $66(60.6)$ & \multirow[t]{2}{*}{$<0.001$} \\
\hline Urban & $126(52.3)$ & $83(62.9)$ & $43(39.4)$ & \\
\hline \multicolumn{5}{|c|}{ Perceived health status } \\
\hline Fair/worse & $66(27.4)$ & $30(22.7)$ & $36(33.0)$ & \multirow[t]{2}{*}{0.074} \\
\hline Good & $175(72.6)$ & $102(77.3)$ & $73(67.0)$ & \\
\hline \multicolumn{5}{|l|}{ Pregnancy term } \\
\hline Pre term & $21(8.7)$ & $10(7.6)$ & $11(10.1)$ & \multirow[t]{2}{*}{0.491} \\
\hline Full term & $220(91.3)$ & $122(92.4)$ & $98(89.9)$ & \\
\hline \multicolumn{5}{|l|}{ Type of delivery } \\
\hline Normal & $150(62.2)$ & $90(68.2)$ & $60(55.0)$ & \multirow[t]{2}{*}{0.036} \\
\hline Caesarian & $91(37.8)$ & $42(31.8)$ & $49(45.0)$ & \\
\hline \multicolumn{5}{|l|}{ ANC visits } \\
\hline$\leq 3$ times & $30(12.4)$ & $7(5.3)$ & $23(21.1)$ & \multirow[t]{2}{*}{$<0.001$} \\
\hline 4 or more & $211(87.6)$ & $125(94.7)$ & $86(78.9)$ & \\
\hline \multicolumn{5}{|l|}{ Birth weight } \\
\hline$<2.5 \mathrm{~kg}$ & $39(16.2)$ & $19(14.4)$ & $20(18.3)$ & \multirow[t]{3}{*}{0.249} \\
\hline $2.5-3.0 \mathrm{~kg}$ & $111(46.1)$ & $57(43.2)$ & $54(49.5)$ & \\
\hline$>3.0 \mathrm{~kg}$ & $91(37.8)$ & $56(42.4)$ & $35(32.1)$ & \\
\hline \multicolumn{5}{|c|}{ Complications during pregnancy } \\
\hline Yes & $86(35.7)$ & $43(32.6)$ & $43(39.4)$ & \multirow[t]{2}{*}{0.268} \\
\hline No & $155(64.3)$ & $89(67.4)$ & $66(60.6)$ & \\
\hline \multicolumn{5}{|c|}{ Complications during and after child birth ${ }^{a}$} \\
\hline Yes & $101(41.9)$ & $43(32.6)$ & $58(53.2)$ & \multirow[t]{2}{*}{0.001} \\
\hline No & $140(58.1)$ & $89(67.4)$ & $51(46.8)$ & \\
\hline \multicolumn{5}{|c|}{ Newborn complications* } \\
\hline Yes & $35(14.5)$ & $13(9.8)$ & $22(20.2)$ & 0.023 \\
\hline No & $206(85.5)$ & $119(90.2)$ & 87 (79.8) & \\
\hline
\end{tabular}


Table 1 Sociodemographic characteristics of respondents (Continued)

\begin{tabular}{llll}
\hline Characteristics & $\begin{array}{l}\text { Total } \\
\boldsymbol{n}=\mathbf{2 4 1}(\%)\end{array}$ & $\begin{array}{l}\text { Disclosed HM use } \\
\boldsymbol{n}=\mathbf{1 3 2}(\%)\end{array}$ & $\begin{array}{l}\text { Did not disclose } \\
\boldsymbol{n}=\mathbf{1 0 9}(\%)\end{array}$ \\
\hline $\begin{array}{l}\text { Congenital malformations/ birth defects on newborn } \\
\text { Yes }\end{array}$ & & \\
No & $7(2.9)$ & $2(1.5)$ & $5(4.6)$ \\
\hline
\end{tabular}

aProlonged labor, fetal distress, abnormal presentation, hypertension, postpartum hemorrhage, etc.

*Lethargy, breathing problems, fever, neonatal jaundice, etc.

\section{Factors associated with disclosure of HM use during pregnancy}

The result of multivariate logistic regression analysis is shown in Table 5. Having secondary education level (OR: 2.25, CI: 1.12-4.51) and attending ANC four or more times (OR: 3.74, CI: 1.41-9.91) were associated with disclosure of HM use to healthcare professionals.

\section{Discussion}

This cross-sectional study examined the characteristics and potential predictors of HM use among pregnant women in Nepal. Our results revealed that $60.3 \%$ of Nepali women used at least one herbal remedy during their previous pregnancy, which was higher compared to the prevalence found in more developed countries [3]. Ginger (46.1\%), turmeric (43.2\%), and lemon tea (29.5\%) were the most frequently used HM among Nepali women. While the use of ginger was well documented in previous literature $[20,21]$, several studies have also found a high prevalence of raspberry leaf, Chinese herbs, Echinacea, and Chamomile uptake [20-24]. These differences in the prevalence and types of HM use can be attributed to various socio-demographic and cultural characteristics.

Comparable to previous findings, cold and flu-like symptoms and nausea/vomiting were the most frequently reported indications for HM use [2, 24, 25]. Ginger was the most commonly used HM modalities to manage those conditions, and its use is prevalent in both pregnant women and the general population [26]. In fact, several systematic reviews indicate that ginger is an effective and safe treatment for pregnancy-induced nausea and vomiting [27-29]. For common cold symptoms, the second most commonly used modality was turmeric, and in Nepal, turmeric powder is usually stirred with hot milk and ingested to treat common cold [30].

However, the consumption of certain herbal remedies without appropriate knowledge can have detrimental effects on the health of the pregnant mother and fetus [5, 31]. For instance, the ingestion of turmeric in pregnancy can stimulate uterine contractions and cause abortion [32]. Basil should be used in pregnancy with caution and under the supervision of a qualified healthcare practitioner [33]. Minor malformations were observed after high doses of neem in pregnant rats, whereas safety information in human pregnancy has not been established yet [34].

Nevertheless, the most frequently reported source of information for HM use during pregnancy in this study were family, friends, and neighbors (98.3\%), and only $7.5 \%$ of respondents obtained the information from health professionals such as doctors, herbalists, midwives, and health workers. Although the credibility of information provided by non-healthcare professionals cannot be guaranteed [35], such dependency on informal sources of information was also seen in other studies [3, 21]. Consistent with previous studies, these findings reflect the need for healthcare professionals to have an adequate understanding of HM use during pregnancy to ensure the safety of mother and child and prevent potential misuse.

As such, despite the high utilization and lack of adequate source of information on HM, only $54.8 \%$ of respondents have disclosed HM use to healthcare professionals during pregnancy. Although the disclosure rate among Nepali women was higher compared to other studies [4, 21, 36, 37], almost half of the respondents failed to communicate with their physicians on HM use, and several studies revealed the negative consequences of poor communication between patients and healthcare professionals on HM use [35, 38]. Furthermore, consistent with previous findings, commonly reported reasons for non-disclosure included doctors not asking about HM use, and pregnant women's belief that it is not important to disclose HM use [10, 39]. These reasons can be attributed to family and cultural influences on HM use. Depending on socio-cultural backgrounds, pregnant women may not consider HM as 'medicines,' and they may not think that it is necessary to disclose HM use to their physicians. This implies that in order to promote transparent communication and ensure proper use of HM among pregnant women, healthcare providers should actively initiate the conversation about the use of non-conventional remedies [10, 40]. Moreover, healthcare providers must have knowledge of herbal activities so that they may provide recommendations to promote the safe use of HM.

Women's education level $(p=0.022)$ and the number of antenatal care (ANC) visits $(p=0.008)$ were identified as potential predictors of disclosure of $\mathrm{HM}$ use to 
Table 2 Types of HM modalities used during pregnancy

\begin{tabular}{|c|c|c|c|}
\hline HM modalities & $n=241(\%)^{*}$ & Reported indications & n (\%)* \\
\hline \multirow[t]{4}{*}{ Ginger } & $111(46.1)$ & Cold/flu & $86(77.5)$ \\
\hline & & Cough & $84(75.7)$ \\
\hline & & Nausea/vomiting & $44(39.6)$ \\
\hline & & Heartburn & $23(20.7)$ \\
\hline \multirow[t]{4}{*}{ Tumeric } & $104(43.2)$ & Cold/flu & $98(94.2)$ \\
\hline & & Cough & $66(63.5)$ \\
\hline & & Skin condition & $8(7.7)$ \\
\hline & & Inflammation & $3(2.9)$ \\
\hline \multirow[t]{4}{*}{ Lemon tea } & $71(29.5)$ & Nausea/vomiting & $66(93)$ \\
\hline & & Heartburn & $26(36.6)$ \\
\hline & & Cough & $19(26.8)$ \\
\hline & & Headache & $3(4.2)$ \\
\hline \multirow[t]{4}{*}{ Tulsi } & $59(24.5)$ & Cough & $53(89.8)$ \\
\hline & & Heartburn & $33(55.9)$ \\
\hline & & Improve immunity & $2(3.4)$ \\
\hline & & Hypertension & $1(1.7)$ \\
\hline \multirow[t]{2}{*}{ Olive oil } & $29(12.0)$ & Massage & $26(89.6)$ \\
\hline & & Skin condition & $13(44.8)$ \\
\hline \multirow[t]{4}{*}{ Neem } & $25(10.4)$ & Skin condition & $15(60.0)$ \\
\hline & & Hypertension & $7(28.0)$ \\
\hline & & Fever & $3(12.0)$ \\
\hline & & Stomach upset & $1(4.0)$ \\
\hline \multirow[t]{4}{*}{ Garlic } & $21(8.7)$ & Abdominal pain & $19(90.5)$ \\
\hline & & Cold/flu & $7(33.3)$ \\
\hline & & Fatigue & $1(4.8)$ \\
\hline & & Hypertension & $1(4.8)$ \\
\hline \multirow[t]{4}{*}{ Aloe vera } & $18(7.5)$ & Skin/hair & $16(88.9)$ \\
\hline & & Constipation & $6(33.3)$ \\
\hline & & Stomach upset & $4(22.2)$ \\
\hline & & Hypertension & $1(5.6)$ \\
\hline \multirow[t]{4}{*}{ Peppermint } & $12(5.0)$ & Cold/flu & $7(58.3)$ \\
\hline & & Abdominal pain & $6(50.0)$ \\
\hline & & Heartburn & $3(25.0)$ \\
\hline & & Nausea/vomiting & $1(8.3)$ \\
\hline \multirow[t]{3}{*}{ Mustard oil } & $10(4.1)$ & Relaxant & $9(90.0)$ \\
\hline & & Fatigue & $1(10.0)$ \\
\hline & & Cold/flu & $1(10.0)$ \\
\hline Rice water & $4(1.7)$ & Burning micturition & $4(100.0)$ \\
\hline Bitter gourd juice & $4(1.7)$ & Hypertension & $4(100.0)$ \\
\hline \multirow[t]{2}{*}{ Cumin seed/powder } & $2(0.8)$ & Stomach upset & $1(50.0)$ \\
\hline & & Fever with headache & $1(50.0)$ \\
\hline Green tea & $1(0.4)$ & Hypertension and headache & $1(100.0)$ \\
\hline
\end{tabular}

*Columns do not add up to $100 \%$ due to the selection of multiple answers 
Table 3 Source of information on HM use

\begin{tabular}{ll}
\hline Source of information $(\boldsymbol{n}=\mathbf{2 4 1})$ & $\mathbf{n}(\%)^{*}$ \\
\hline Family/friends/neighbor & $236(98.3)$ \\
Newspaper/magazine & $41(17.1)$ \\
Doctor & $11(4.6)$ \\
Herbalist & $5(2.1)$ \\
TV/radio/internet & $4(1.7)$ \\
Midwife/health worker & $2(0.8)$ \\
Temple/religious text & $1(0.4)$ \\
Self & $1(0.4)$ \\
\hline *Columns do not add up to 100\% due to the selection of multiple answers
\end{tabular}

physicians. Previous studies also found that higher educational attainment was associated with disclosure of non-conventional medicine use [41, 42]. These associations could be attributed to people with higher education levels having better health literacy, which may influence them to seek advice and information on HM use from healthcare providers [43, 44]. Furthermore, building mutual trust through regular antenatal care visits may have affected pregnant women to communicate with their physicians on HM use. Similarly, previous studies also found a positive correlation between the disclosure of non-conventional medicine use and frequent doctor visits and higher scores on the patient-provider relationship scale $[11,45]$.

The limitations of this study include recall bias and generalizability of the results, as the data was collected retrospectively at a single hospital in Kathmandu city. However, the hospital, where the study was conducted, is considered as the largest public tertiary maternity hospital in Nepal. Furthermore, in order to reduce recall bias, the survey was taken among postpartum women admitted to the inpatient unit before they were formally discharged from the facility.

Table 4 Reason for HM use and non-disclosure

\begin{tabular}{ll}
\hline Reason for HM use $(\boldsymbol{n}=\mathbf{2 4 1})$ & $\mathbf{n}(\%)^{*}$ \\
I believe it is safe & $160(66.4)$ \\
Family tradition/culture & $152(63.1)$ \\
I believe it is effective & $116(48.1)$ \\
It is cheap and accessible & $25(10.4)$ \\
Reason for non-disclose $(\boldsymbol{n}=\mathbf{1 0 9})$ & $\mathbf{n}(\%)$ \\
Doctors did not ask & $43(39.8)$ \\
It was not important & $32(29.6)$ \\
Should have informed but forgot & $19(17.6)$ \\
Afraid of doctors' response & $12(11.1)$ \\
No ANC visit & $2(1.9)$ \\
\hline
\end{tabular}

*Columns do not add up to $100 \%$ due to the selection of multiple answers
Table 5 Multivariate logistic regression analysis between demographic and pregnancy-related factors and physician disclosure on HM use

\begin{tabular}{|c|c|c|c|}
\hline Characteristics & OR & $95 \% \mathrm{Cl}$ & $P$-value \\
\hline \multicolumn{4}{|l|}{ Education level } \\
\hline Primary and under & 1 & Ref & \\
\hline Secondary & 2.255 & $1.127-4.513$ & 0.022 \\
\hline College or above & 1.575 & $0.656-3.783$ & 0.310 \\
\hline \multicolumn{4}{|l|}{ Household income } \\
\hline Low & 1 & Ref & \\
\hline Middle & 1.072 & $0.479-2.401$ & 0.865 \\
\hline High & 1.362 & $0.668-2.780$ & 0.395 \\
\hline \multicolumn{4}{|l|}{ Employment status } \\
\hline Yes & 1 & Ref & \\
\hline No & 0.883 & $0.376-2.073$ & 0.774 \\
\hline \multicolumn{4}{|l|}{ Residence } \\
\hline Rural & 1 & Ref & \\
\hline Urban & 1.807 & $0.985-3.315$ & 0.056 \\
\hline \multicolumn{4}{|l|}{ ANC visits } \\
\hline$\leq 3$ times & 1 & Ref & \\
\hline 4 or more & 3.747 & $1.416-9.915$ & 0.008 \\
\hline \multicolumn{4}{|l|}{ Type of delivery } \\
\hline Normal & 1 & Ref & \\
\hline Caesarian & 0.556 & $0.307-1.009$ & 0.054 \\
\hline
\end{tabular}

Complications during and after child birth ${ }^{\mathrm{a}}$

$\begin{array}{llll}\text { Yes } & 1 & \text { Ref } & \\ \text { No } & 1.596 & 0.890-2.862 & 0.117 \\ \text { Newborn complications } & & & \\ \text { Yes } & 1 & \text { Ref } & \\ \text { No } & 2.183 & 0.962-4.953 & 0.062\end{array}$

\section{Conclusion}

This study found that the use of HM during pregnancy was common in Nepal. However, most women obtained HM-related information from informal sources and did not disclose HM use to their physicians. ANC visits and women's education levels were found to be associated with disclosure of HM use to physicians. Therefore, to provide optimal care and promote coordination between HM and conventional medicine, healthcare providers should stay up to date with the knowledge of HM use. Furthermore, integration of questions on HM use into routine patient assessments during ANC should be considered to facilitate active communication on HM use during pregnancy. Lastly, public education and awareness programs on the safe use of HM should be developed to encourage pregnant women's disclosure of HM use. 


\section{Supplementary Information}

The online version contains supplementary material available at https://doi. org/10.1186/s12906-020-03142-9

\section{Additional file 1.}

\section{Abbreviations}

HM: Herbal medicine; ANC: Antenatal care

\section{Acknowledgments}

The authors would like to express their sincere gratitude to all the participants for their cooperation and willingness to share their experience.

\section{Authors' contributions}

$M A, H B, J H$, and DW were responsible for the study concept and design. DW $\mathrm{HB}$, and $\mathrm{JH}$ analyzed the data and drafted the manuscript. MA and DW contributed to the designing of data collection tools and data collection. $M A, H B, J H$, and DW critically reviewed the manuscript and contributed intellectual content. All authors read and approved the final manuscript.

\section{Funding}

None.

\section{Availability of data and materials}

The data will be accessible by contacting the corresponding author of this study.

\section{Ethics approval and consent to participate}

Ethical approval for the study was acquired from the Institutional Review Board on Human Subjects Research and Ethics Committees, Hanyang University (HYI-17-067-2). Additional formal permission was approved by the Institutional Review Committee of the Paropakar Maternity and Women's Hospital in Kathmandu, Nepal (58-11 ka-259). Enrollment of the respondents was voluntary, and all patients gave written informed consent to participate in the study.

\section{Consent for publication}

Not applicable.

\section{Competing interests}

The authors have no conflicts of interest to declare.

\section{Author details}

'School of Public Health, Dow University of Health Sciences, Karachi, Pakistan. ${ }^{2}$ Department of Global Health and Development, Graduate School, Hanyang University, Seoul, South Korea. ${ }^{3}$ Institute of Health Services Management, Hanyang University, Seoul, South Korea. ${ }^{4}$ Department of Obstetrics and Gynecology, Hanyang University College of Medicine, Seoul, South Korea. ${ }^{5}$ Department of Preventive Medicine, Hanyang University College of Medicine, 222 Wangsimni-ro, Seongdong-gu, Seoul 133-791, South Korea.

Received: 16 May 2020 Accepted: 31 October 2020

Published online: 10 November 2020

\section{References}

1. Traditional, complementary and integrative medicine [https://www.who.int/ traditional-complementary-integrative-medicine/about/en/]

2. Bayisa B, Tatiparthi R, Mulisa E. Use of herbal medicine among pregnant women on antenatal care at Nekemte hospital, Western Ethiopia. Jundishapur J Nat Pharm Prod. 2014;9:4.

3. Hall HG, Griffiths DL, McKenna LG. The use of complementary and alternative medicine by pregnant women: a literature review. Midwifery 2011;27(6):817-24.

4. James PB, Bah AJ, Tommy MS, Wardle J, Steel A. Herbal medicines use during pregnancy in Sierra Leone: an exploratory cross-sectional study. Women Birth. 2018:31(5):e302-9.

5. Ahmed M, Hwang JH, Choi S, Han D. Safety classification of herbal medicines used among pregnant women in Asian countries: a systematic review. BMC Complement Altern Med. 2017;17(1):489.
6. Strouss L, Mackley A, Guillen U, Paul DA, Locke R. Complementary and alternative medicine use in women during pregnancy: do their healthcare providers know? BMC Complement Altern Med. 2014;14(1):85.

7. Harrigan J. Patient disclosure of the use of complementary and alternative medicine to their obstetrician/gynaecologist. J Obstet Gynaecol. 2011;31(1): 59-61.

8. Lim A, Cranswick N, South M. Adverse events associated with the use of complementary and alternative medicine in children. Arch Dis Child. 2011; 96(3):297-300

9. Laelago T. Herbal medicine use during pregnancy: benefits and untoward effects. In: Herbal medicine. IntechOpen; 2018.

10. Foley $\mathrm{H}$, Steel A, Cramer H, Wardle J, Adams J. Disclosure of complementary medicine use to medical providers: a systematic review and meta-analysis. Sci Rep. 2019;9(1):1573

11. Kennedy J, Wang C-C, Wu C-H. Patient disclosure about herb and supplement use among adults in the US. Evid Based Complement Alternat Med. 2008:5(4):451-6.

12. Women's NCCf, Health Cs. Antenatal care: routine care for the healthy pregnant woman: RCOG press; 2008.

13. Palaniappan B. Role of antenatal care in safe motherhood. J Indian Med Assoc. 1995:93(2):53.

14. Kadayat TM, Bist G, Parajuli A, Karki R, Kaundinnyayana A, Dhami N. Patterns and perception of complementary and alternative medicine use by patients in western Nepal. J Public Health. 2012;20(3):297-303.

15. Devkota S, Chaudhary RP, Werth S, Scheidegger C. Indigenous knowledge and use of lichens by the lichenophilic communities of the Nepal Himalaya. J Ethnobiol Ethnomed. 2017;13(1):15.

16. Kunwar RM, Nepal BK, Kshhetri HB, Rai SK, Bussmann RW. Ethnomedicine in Himalaya: a case study from Dolpa, Humla, Jumla and mustang districts of Nepal. J Ethnobiol Ethnomed. 2006:2(1):27.

17. Rahman AA, Sulaiman SA, Ahmad Z, Salleh H, Daud WNW, Hamid AM. Women's attitude and sociodemographic characteristics influencing usage of herbal medicines during pregnancy in Tumpat Distric, Kelantan. Southeast Asian J Trop Med Public Health. 2009:40(2):330.

18. Hwang JH, Kim Y-R, Ahmed M, Choi S, Al-Hammadi NQ, Widad NM, et al. Use of complementary and alternative medicine in pregnancy: a crosssectional survey on Iraqi women. BMC Complement Altern Med. 2016;16(1): 191.

19. Cuzzolin L, Francini-Pesenti F, Verlato G, Joppi M, Baldelli P, Benoni G. Use of herbal products among 392 Italian pregnant women: focus on pregnancy outcome. Pharmacoepidemiol Drug Saf. 2010;19(11):1151-8.

20. Forster DA, Denning A, Wills G, Bolger M, McCarthy E. Herbal medicine use during pregnancy in a group of Australian women. BMC Pregnancy Childbirth. 2006;6(1):21.

21. Holst L, Wright D, Haavik S, Nordeng $H$. The use and the user of herbal remedies during pregnancy. J Altern Complement Med. 2009;15(7):787-92.

22. Holst L, Nordeng $H$, Haavik S. Use of herbal drugs during early pregnancy in relation to maternal characteristics and pregnancy outcome. Pharmacoepidemiol Drug Saf. 2008;17(2):151-9.

23. Moussally K, Oraichi D, Bérard A. Herbal products use during pregnancy: prevalence and predictors. Pharmacoepidemiol Drug Saf. 2009;18(6):454-61.

24. Nordeng H, Havnen GC. Use of herbal drugs in pregnancy: a survey among 400 Norwegian women. Pharmacoepidemiol Drug Saf. 2004 13(6):371-80

25. Mekuria AB, Erku DA, Gebresillassie BM, Birru EM, Tizazu B, Ahmedin A. Prevalence and associated factors of herbal medicine use among pregnant women on antenatal care follow-up at University of Gondar referral and teaching hospital, Ethiopia: a cross-sectional study. BMC Complement Altern Med. 2017:17(1):86.

26. Rotblatt M, Ziment I. Evidence-based herbal medicine: Hanley \& Belfus; 2002.

27. Ernst $E$, Pittler M. Efficacy of ginger for nausea and vomiting: a systematic review of randomized clinical trials. Br J Anaesth. 2000;84(3):367-71.

28. Viljoen E, Visser J, Koen N, Musekiwa A. A systematic review and metaanalysis of the effect and safety of ginger in the treatment of pregnancyassociated nausea and vomiting. Nutr J. 2014;13(1):20.

29. Ding $M$, Leach $M$, Bradley $H$. The effectiveness and safety of ginger for pregnancy-induced nausea and vomiting: a systematic review. Women Birth. 2013;26(1):e26-30.

30. Yadav RP, Tarun G Versatility of turmeric: a review the golden spice of life. $J$ Pharm Phytochem. 2017;6(1):41-6. 
31. Bruno LO, Simoes RS, de Jesus SM, Girão MJBC, Grundmann O. Pregnancy and herbal medicines: an unnecessary risk for women's health-a narrative review. Phytother Res. 2018;32(5):796-810.

32. Gruenwald J, Brendler T, Jaenicke C. PDR for herbal medicines: Thomson, Reuters; 2007.

33. Kennedy D, Lupattelli A, Koren G, Nordeng H. Safety classification of herbal medicines used in pregnancy in a multinational study. BMC Complement Altern Med. 2016;16(1):102.

34. Srivastava M, Raizada R. Assessment of embryo/fetotoxicity and teratogenicity of azadirachtin in rats. Food Chem Toxicol. 2001;39(10):1023-7.

35. Wardle JJL, Adams J. Indirect and non-health risks associated with complementary and alternative medicine use: an integrative review. Eur J Integr Med. 2014;6(4):409-22.

36. Ahmed M, Hwang JH, Hasan MA, Han D. Herbal medicine use by pregnant women in Bangladesh: a cross-sectional study. BMC Complement Altern Med. 2018;18(1):333.

37. Mothupi MC. Use of herbal medicine during pregnancy among women with access to public healthcare in Nairobi, Kenya: a cross-sectional survey. BMC Complement Altern Med. 2014;14(1):432.

38. Robinson A, McGrail MR. Disclosure of CAM use to medical practitioners: a review of qualitative and quantitative studies. Complementary Ther Med. 2004:12(2-3):90-8.

39. Faith J, Thorburn S, Tippens KM. Examining CAM use disclosure using the behavioral model of health services use. Complementary Ther Med. 2013; 21(5):501-8

40. Hall HR, Jolly K. Women's use of complementary and alternative medicines during pregnancy: a cross-sectional study. Midwifery. 2014;30(5):499-505.

41. Saxe GA, Madlensky L, Kealey S, Wu DP, Freeman KL, Pierce JP. Disclosure to physicians of CAM use by breast cancer patients: findings from the Women's healthy eating and living study. Integrative Cancer Ther. 2008;7(3): 122-9.

42. Liu C, Yang Y, Gange SJ, Weber K, Sharp GB, Wilson TE, et al. Disclosure of complementary and alternative medicine use to health care providers among HIV-infected women. AIDS Patient Care STDs. 2009;23(11):965-71.

43. Jansen T, Rademakers J, Waverijn G, Verheij R, Osborne R, Heijmans M. The role of health literacy in explaining the association between educational attainment and the use of out-of-hours primary care services in chronically ill people: a survey study. BMC Health Serv Res. 2018;18(1):394.

44. Yukawa K, Ishikawa H, Yamazaki Y, Tsutani K, Kiuchi T. Patient health literacy and patient-physician communication regarding complementary and alternative medicine usage. Eur J Integrative Med. 2017;10:38-45.

45. Chao MT, Wade C, Kronenberg F. Disclosure of complementary and alternative medicine to conventional medical providers: variation by race/ ethnicity and type of CAM. J Natl Med Assoc. 2008;100(11):1341-9.

\section{Publisher's Note}

Springer Nature remains neutral with regard to jurisdictional claims in published maps and institutional affiliations.

Ready to submit your research? Choose BMC and benefit from:

- fast, convenient online submission

- thorough peer review by experienced researchers in your field

- rapid publication on acceptance

- support for research data, including large and complex data types

- gold Open Access which fosters wider collaboration and increased citations

- maximum visibility for your research: over $100 \mathrm{M}$ website views per year

At $\mathrm{BMC}$, research is always in progress.

Learn more biomedcentral.com/submissions 